Revista de Estudios Histórico-Jurídicos

[Sección derecho romano]

XLII (Valparaíso, Chile, 2020)

[pp. 129-143]

\title{
DOS EXCEPCIONES PROCESALES CON UNA ÚNICA FINALIDAD
}

[Two procedural exceptions with a single purpose]

\author{
Margarita Fuenteseca DegenefFe* \\ Universidad de Vigo, España
}

\begin{abstract}
RESUMEN
Existen en el Digesto tres pasajes en los que se plantea y resuelve el mismo supuesto de hecho. El análisis conjunto de los tres sirve para explicar el funcionamiento de las dos excepciones procesales que podía oponer el comprador a non domino frente a una posible acción reivindicatoria del vendedor: la exceptio in factum comparata vel doli mali y la exceptio rei venditae et traditae. Ambas servían para una única finalidad, consistente en que el vendedor no dueño, incluso aunque se convirtiese en dueño tras la venta inicial a non domino, nunca pudiese vencer con una acción reivindicatoria frente a su comprador.

Palabras Clave

Exceptio in factum comparata vel doli mali-exceptio rei venditae et traditae - venta a non domino - reivindicatio.
\end{abstract}

Abstract

There are three texts in the Digest in which the same factual assumption is posed and resolved. The joint analysis of the three serves to explain the operation of the two procedural exceptions that the non domino buyer could oppose against a possible claim by the seller: the exceptio in factum comparata vel doli mali and the exceptio rei venditae et traditae. Both served a single purpose, namely that the nonowner seller, even if he became owner after the initial a non domino sale, could never win with a claim action against the buyer.

\section{KeY Words}

Exceptio in factum comparata vel doli mali - exceptio rei venditae et traditae - a non domino sell - reivindicatio.

RECIBIDO el 13 de septiembre de 2019 y ACEPTADO el 15 de abril de 2020

\section{Cuestión metodológica inicial}

Hay en el Digesto tres pasajes en los que se plantea exactamente el mismo supuesto de hecho, en forma de caso práctico. Uno de ellos es del jurista Pomponio,

* Catedrática de Derecho Romano en la Facultad de Ciencias Jurídicas y del Trabajo de la Universidad de Vigo. Dirección postal: Campus As Lagoas número 36310, Vigo, Pontevedra, España. Correo electrónico: mfd@uvigo.es. 
y los otros dos son de Ulpiano, de sus comentarios ad Edictum ${ }^{1}$.

Hasta ahora se ha abordado el estudio de estos tres pasajes intentando detectar, mediante su cotejo literal, hasta qué punto habrían sido objeto de interpolación por los compiladores de Justiniano, que, en la confección del Digesto, habrían alterado los textos de los juristas clásicos para adaptarlos a las condiciones socio-jurídicas imperantes en la fase final de vigencia del derecho romano. Pero con la comparación o cotejo literal de estos textos, buscando la supuesta adición o supresión de una o de varias de sus palabras, hasta ahora solo se han propuesto conjeturas e hipótesis bastante dispares entre sí, tantas como estudios se han publicado.

Por este motivo parece más acertado, para comenzar con el análisis de estos tres pasajes, tomar como punto de partida un dato, que es real y verdadero: en los tres pasajes el supuesto de hecho o caso práctico que se resuelve es exactamente el mismo. La cuestión que debe ser aclarada, entonces, no es si hubo o no interpolación por parte de los compiladores, sino porqué estos desobedecieron a las órdenes del emperador Justiniano ${ }^{2}$ de eliminar repeticiones innecesarias y de suprimir lo superfluo en la confección del Corpus Iuris ${ }^{3}$.

Como vamos a ver, es posible encontrar el motivo que justifica la subsistencia por triplicado del mismo supuesto de hecho si se tiene especialmente en cuenta la ubicación de cada uno de los tres pasajes en diferentes títulos del Digesto. El mismo supuesto de hecho se utiliza tres veces para explicar el funcionamiento de las excepciones y de las réplicas que tenían entre sí el comprador a non domino y el vendedor no dueño, cuando este último, tras la venta inicial, se convierte en dueño.

El problema aquí se plantea porque la emptio venditio en Roma, como dice Arangio-Ruiz", se caracteriza por la "mera obbligatorietă” y, por tanto, añadimos,

${ }^{1}$ Las coincidencias y repeticiones contenidas en los pasajes del Digesto y del Codex vienen siendo estudiadas desde Müller, Peter, De studio iuris tractando diatribe, Editio secunda (Jena Bauhöfer, 1678) que contiene un capítulo de "Leges in Pandectarum concordantes" y otro sobre "Leges in Digestis et Codice geminatae et repetitae". Luego fue Bluhme quien las rebautizó como leges geminatae. BluHME, Friedrich, De geminatis et similibus quae in Digestis invenientur capitis (Jena, 1820).

${ }^{2}$ Justiniano ordena que, de los libros antiguos, se suprima lo que no está correctamente ubicado, o es superfluo o incompleto en la Const. Deo auctore, C. 1, 17, 7: "Sed et hoc studiosum vobis esse volumus, ut, si quid in veteribus non bene positum libris inveniatis, vel aliquod superfluum, vel minus perfectum supervacua longitudine semota, et quod imperfectum est repleatis, et omne opus moderatum et quam pulcherrimum ostendatis [...]", y que se supriman las antinomias y que haya entre todas las partes del código una sola concordancia, en Deo auctore, C. 1, 17, 8: "nulla [...] antinomia (sic enim a vetustate Graeco vocablo nuncupatur) aliquem sibi vindicet locum, sed sit una concordia, una consequentia, adversario nemine constituto".

${ }^{3}$ Nos acercamos más bien al método descrito por GARCÍA GARRIDO, Manuel Jesús, Redacciones coincidentes ("leges geminatae") y casos jurisprudenciales semejantes ("capita similia") en Estudios de derecho romano en honor de Álvaro d'Ors (Pamplona, EunsA, 1987), I, p. 519. Propone realizar la comparación de los textos no por sus identidades relacionales externas, sino por las semejanzas de su contenido, especialmente por las coincidencias de los casos y supuestos de hecho tratados en los textos jurisprudenciales. Según García Garrido, se debe realizar la comparación o cotejo casuístico de textos que lleva a interesantes resultados sobre el caso originario y sus diferentes redacciones y también sobre las reglas que se deducen de los casos.

${ }^{4}$ Arangio-RuIZ, Vincenzo, La compravendita in diritto romano (1956, reimpresión, Napoli, Jovene, 1987), I, p. 88 ss. 
no es un negocio jurídico traslativo de la propiedad, sino un contrato consensual, con el que se establece una relación meramente obligacional entre las partes. Con el acuerdo sobre la cosa y el precio el contrato se perfecciona entre las partes, y produce sus plenos efectos. Y si el vendedor no es dueño, el posible perjuicio causado al comprador, cuando este tiene que restituir la cosa adquirida a su verdadero dueño, se solventa mediante la imposición de la responsabilidad por evicción al vendedor. Pero, ¿qué sucede si el vendedor no dueño se convierte tras la venta en dueño, e interpone una acción reivindicatoria (con la que, teniendo el título de dueño, siempre vencería) frente al que fue su comprador?

La solución que se impuso en Roma es que, en este caso, debía ser mantenido el comprador en su adquisición. Y esto se lograba mediante el funcionamiento de dos excepciones (con sus correspondientes réplicas), con las que el comprador vencía en el litigio frente al vendedor, que tenía el título de propietario. Este complejo caso se resuelve en los tres pasajes que vamos a analizar aquí.

Se trata de D. 44, 4, 4, 32, de D. 21, 3, 2 y de D. 6, 1, 72. El idéntico supuesto de hecho que se plantea en estos es el siguiente: se celebró por Ticio una venta (por medio de traditio y con pago del precio) de un fundo que pertenecía a Sempronio, y luego el mismo Ticio, convertido en dueño por ser heredero de Sempronio, habiendo vendido el mismo fundo a un tercero (también por medio de traditio), lo reivindica del primer comprador. Y la solución, aunque no formulada exactamente con las mismas palabras, es la misma en estos tres pasajes: debe ser amparado el primer comprador por el pretor.

Vamos, pues, a intentar encontrar el motivo que podría explicar la subsistencia en el Digesto de estos tres pasajes con el mismo supuesto de hecho 5 .

\section{LA EXCEPTIO IN FACTUM COMPARATA VEL DOLI MALI}

Comenzamos por el pasaje que, de los tres, contiene información más detallada. Se trata de D. 44, 4, 4, 32, de Ulpiano libro LXXVI ad Edictum ${ }^{6}$. Aquí, el supuesto de hecho es el mismo que en los otros dos textos mencionados (D. 21, 3,2 y D. 6, 1, 72). Se celebró por Ticio una venta (por medio de traditio y con pago del precio) de un fundo que pertenecía a Sempronio, y luego el vendedor

${ }^{5}$ Vid. sobre estos tres textos que se encuentran por triplicado en el Digesto HERNANDo LERA, Julio, Una corrección paligenésica al libro 16 de Ulpiano ad Edictum, en Boletín de la Facultad de Derecho, 10-11 (1996, UNED), pp. 143-160. El autor detecta un posible error (humano) cometido por los compiladores a la hora de confeccionar el Digesto. Aquí proponemos, en cambio, partir de la coherente labor de los compiladores, para intentar encontrar el motivo que justificaría el mantenimiento por triplicado del mismo supuesto de hecho en el Digesto.

${ }^{6}$ D. 44, 4, 4, 32: "Si a Titio fundum emeris, qui Sempronii erat, isque tibi traditus fuerit pretio soluto, deinde Titius Sempronio heres extiterit, et eundem fundum Maevio vendiderit et tradiderit, Iulianus ait, aequius esse Praetorem te tueri, quia, et si ipse Titius fundum a te peteret, exceptione in factum comparata, vel doli mali summoveretur, et si ipse eum possideret, et Publiciana peteres, adversus excipientem: "si non suus esset", replicatione utereris, ac per hoc intellegeretur, eum fundum rursum vendidisse, quem in bonis non haberet". Vid. Lenel, Otto, Palingenesia Iuris Civilis, vol. alt. (Graz, Austria, Akademische Druck-U. Verlagsanstalt, 1960), col. 865, no 1681, sitúa el pasaje bajo el título "Doli mali vel metus". 
Ticio, convertido en heredero de Sempronio, vende el mismo fundo a Mevio (también por medio de traditio). Ulpiano, remitiéndose en la opinión de Juliano, afirma que es más equitativo (aequius esse) que el pretor ampare al comprador.

La excepción que, según Ulpiano, podía utilizar el comprador a non domino frente a Ticio, el vendedor reivindicante, es la excepción de que la cosa fue comprada de hecho (in factum comparata), o su equivalente, la excepción de dolo malo (vel doli mali). Pero además, afirma Ulpiano, la misma excepción se podía utilizar como replicatio. Si era el propio Ticio, vendedor no dueño, el que poseía el fundo, podía el comprador a non domino vencerle siempre con la actio Publiciana, porque si el vendedor pretende paralizar su acción con la excepción de que aquel no era dueño (si non suus esset), podía el comprador oponer esa misma replicatio, alegando que efectivamente, o de hecho, había comprado la cosa (in factum comparata vel doli mali).

Pero es en el inciso final del texto donde encontramos la explicación en la que Ulpiano fundamenta la aplicación de la mencionada exceptio y también de la replicatio: se entiende que Ticio vendió de nuevo (rursum) un fundo que no tenía in bonis. Pero no se puede olvidar que, sin embargo, el propio Ulpiano, en el mismo supuesto de hecho, dice que en la segunda venta Ticio ya había heredado de Sempronio. Por tanto, la conclusión que necesariamente se obtiene de esta explicación final ulpianea es que la primera venta, efectivamente, fue realizada a non domino, pero, además, tampoco el vendedor Ticio tenía el fundo in bonis cuando realizó la segunda venta, aunque en ese momento ya se había convertido en dueño al heredar a Sempronio.

La clave está entonces en la venta inicial realizada a non domino, que es plenamente eficaz entre las partes contratantes desde el momento de su celebración ${ }^{7}$. Esto es conforme al normal funcionamiento de la emptio venditio, contrato consensual que se perfecciona por medio del acuerdo de las partes sobre la cosa y el precio, cuya validez o eficacia inter partes no depende de que sea realizada por el que es dueño de la cosa objeto de venta. En el caso de que fuese realizada por quien no era dueño, quedaría salvaguardado el interés patrimonial tanto del comprador a non domino como del verdadero propietario mediante la imposición de la responsabilidad por evicción al vendedor. Por tanto, salvo en el caso de la acción reivindicatoria interpuesta por el verdadero propietario, la venta por un no dueño producía todos sus efectos entre las partes contratantes desde el momento de su celebración.

Así se explica que, según el pasaje aquí analizado, tenga el primer comprador la excepción frente a Ticio, el vendedor reivindicante, porque de hecho (in factum) compró la cosa, esto es, con la excepción paraliza el comprador la reivindicatio del vendedor que no era dueño en el momento de la venta porque, de hecho, la

\footnotetext{
${ }^{7}$ Según CANNATA, Carlo Augusto, La compravendita consensuale romana: significato di una struttura, en VACCA, Letizia (a cura di), Vendita e trasferimento della proprietà nella prospettiva storico-comparatistica (Milano, Giuffré, 1991), II, p. 426, el contrato de venta (de una res mancipi) consiste en un puro acuerdo informal, y, en consecuencia, no puede tener más que efectos obligatorios.
} 
venta (a non domino) fue realizada entre ellos y, por tanto, producía sus efectos ${ }^{8}$. Y sobre la misma base se fundamenta la replicatio, que, según Ulpiano tenía este mismo comprador cuando interponía la actio Publiciana contra el vendedor, si este le paralizaba la acción con la exceptio dominii. La venta (a non domino) se había celebrado de hecho entre ellos.

La situación que Ulpiano describe en este pasaje es la de una doble venta de un mismo fundo, celebrada por el vendedor Ticio ${ }^{9}$. Realizó una primera venta a non domino, que producía todos sus efectos entre comprador y vendedor, y después una segunda venta, esta vez, siendo ya dueño. La conducta dolosa del vendedor Ticio consistía entonces, en reivindicar frente al primer comprador, una vez realizada la segunda venta. El vendedor Ticio entonces será repelido con la exceptio in factum comparata vel doli mali porque, como explica claramente Ulpiano en el último inciso del pasaje, vendió de nuevo una cosa que no tenía in bonis.

La utilización de la mencionada exceptio se fundamenta, por tanto, en la existencia de una venta a non domino inicial, que es plenamente eficaz entre las partes celebrantes, y entonces es doloso el vendedor que reivindica frente al primer comprador pretendiendo hacer prevalecer su título de dueño, adquirido con posterioridad a esa primera venta, habiendo además vendido por segunda vez el mismo fundo.

Por otra parte, otro dato muy relevante es la inclusión del pasaje aquí analizado en el título 44. 4 del Digesto, titulado De doli mali et metus exceptione. Se trata, pues, de un supuesto específico de dolus malus, que puede tener lugar en la

${ }^{8}$ KosChaKer, Paul, Fr.4.32 D.44.4 Contributo alla storia della convalida nel diritto romano, en IURA, 4 (1953), pp. 1 ss, ve en este pasaje un caso de convalidación de la venta a non domino inicial. Koschaker entiende que la venta se convalida una vez que se hizo dueño el vendedor al heredar de Sempronio. Pero esto no es propiamente así, ya que la venta inicial a non domino produce plenos efectos entre las partes contratantes desde el inicio, salvo que reivindicase el verdadero propietario, en cuyo caso el vendedor respondería por evicción. Por eso la venta no necesita de convalidación alguna, sino que se trata, más bien, en este pasaje, de que el vendedor no obtenga beneficio alguno de esta venta a non domino realizada por él.

${ }^{9} \mathrm{La}$ exceptio aquí analizada era aplicable entre comprador y vendedor, siendo su resultado siempre la protección del primer comprador, aunque hubiese sido a non domino. Y la validez de la venta a non domino también sirve de base para la solución que nos dan los juristas romanos cuando, en un caso de doble venta, realizada por el mismo vendedor o por vendedores distintos, son los dos compradores los que litigan entre ellos: será amparado el que en primer lugar tomó posesión de la cosa vendida, aunque hubiese comprado de un no dueño. En efecto, afirma Ulpiano (D. 6, 2, 9, 4) que en el caso de que una misma cosa se hubiese vendido por separado a dos compradores de buena fe, tendrá la actio Publiciana aquel al que primero le fue entregada la cosa, también en el caso de que el vendedor no fuese dueño. Lo mismo resuelve Neracio (D. 19, 1, 31, 2), para el caso de ventas a non domino realizada por el mismo vendedor o por vendedores distintos. En ambos casos la preferencia la tiene el que primero tomó posesión de la cosa, sea mueble o inmueble. Además, tiene mejor posición el que posee que el que pide, según D. 6, 3, 9, 4: "[...] quod si a diversis dominis emerint, melior causa sit possidentis quam petentis". Para la problemática que suscita la doble venta, consúltese LóPEz PEDREIRA, Adela, ${ }^{E l}$ problema de la doble venta de una cosa: del derecho romano clásico al artículo 1473 del Código Civil español, en Murillo Villar, Alfonso (coord.), La responsabilidad civil: de Roma al derecho moderno, IV Congreso Internacional y VII Congreso Iberoamericano de Derecho Romano (Burgos, Universidad de Burgos, 2001), pp. 455-468. 
relación contractual bilateral establecida entre comprador y vendedor en la emptio venditio. El comprador de un fundo por medio de traditio y con pago del precio solo adquiría la condición de propietario pretorio (possessor ad usucapionem) y no la condición de dominus. Como propietario pretorio sucumbiría, si no fuese por la oposición de esta excepción, frente al vendedor a non domino convertido luego en dominus (Ticio es heredero de Sempronio). Pero también necesitaba la correspondiente replicatio, porque como propietario pretorio podía exigir la restitución de la possessio del fundo frente a todos con la actio Publiciana, pero si el que retenía la possessio era Ticio, que le había vendido el fundo a non domino, y que, además, oponía la excepción alegando que era él el verdadero dueño, habiendo vuelto a vender el fundo, entonces era cuando el comprador vencía con la correspondiente replicatio in factum comparata vel doli mali.

En conclusión, de la venta inicial a non domino no podía obtener beneficio el vendedor Ticio. Si no era dueño cuando realizó la primera venta, no podía luego vencer frente al comprador con la interposición de una reivindicatio, si, además, vendió el fundo por segunda vez, aunque en esta segunda venta ya pudiese demostrar que era dueño. En este caso su reivindicación del fundo por parte de Ticio era dolosa, y el primer comprador (a non domino) sería amparado por el pretor con la exceptio rei comparata vel doli mali (o bien con la replicatio del mismo nombre). La propia naturaleza jurídica de la emptio venditio exigía la aplicación de los instrumentos procesales, la exceptio o la replicatio, para evitar una posible resolución judicial carente de equidad en ese caso concreto.

\section{LA EXCEPTIO REI VENDITAE ET TRADITAE}

El mismo supuesto de hecho, como hemos dicho, aparece asimismo en otro pasaje del Digesto. Se trata de D. 21, 3, 2, de Pomponio (libro secundo ex Plautio) ${ }^{10}$. La solución que da Pomponio al mismo supuesto de hecho es exactamente la misma: el primer comprador debe ser protegido por el pretor, porque tiene una excepción contra el vendedor Ticio. Pero la diferencia radica en que el jurista no dice de qué excepción se trata. En definitiva, lo que dice Pomponio es que está protegido siempre el primer comprador a non domino frente al vendedor, porque puede paralizar la acción reivindicatoria con una excepción, y también tiene una acción contra él, la acción Publiciana.

Puesto que Pomponio no menciona el nombre de la exceptio que tendría el comprador a non domino, por la ubicación sistemática del pasaje en el Digesto (D. 21, 3: De exceptione rei venditae et traditae) podemos deducir que se trata de la exceptio rei venditae et traditae. Pero hay que tener en cuenta que también sería aplicable la exceptio in factum comparata vel doli mali, que es la que propone Ulpiano para el mismo supuesto de hecho en el pasaje antes analizado (D. 44,

${ }^{10}$ D. 21, 3, 2: "Si a Titio fundum emeris, qui Sempronii erat, isque tibi traditus fuerit, pretio autem soluto Titius Sempronii heres extiterit, et eundem fundum Maevio vendiderit et tradiderit, Iulianus ait aequius esse priorem te tueri, quia, et si ipse Titius fundum a te peteret, exceptione summoveretur et si ipse Titius eum possideret, Publiciana peteres". Lenel, Otto, cit. (n. 6), col. 79, no 332, sitúa este pasaje en Pomponio libro secundo ex Plautio libri VII. 
4, 4, 32). En consecuencia, habría que determinar cuándo procede la aplicación de la exceptio rei venditae et traditae a este mismo supuesto de hecho. Esto solo podía suceder, lógicamente, cuando el vendedor, al interponer la reivindicatio, no había sido doloso.

Para la aclaración de esta cuestión es de gran ayuda otro pasaje del Digesto, insertado en el mismo título D. 21, 3: De exceptione rei venditae et traditae. Según Ulpiano (D. 21, 3, $1 \mathrm{pr}^{11}$ ), si el que vendió un fundo ajeno, habiéndose hecho dueño después, reclama al comprador, puede este repelerle con la exceptio rei venditae et traditae. Por tanto, la conducta del vendedor no dueño, que reivindica el fundo vendido cuando, tras la venta, se ha convertido en dueño del mismo, no es en sí misma dolosa, porque la exceptio que le corresponde al comprador es la exceptio rei venditae et traditae (y no la exceptio doli). El motivo es que, en general, no se puede considerar dolosa la reivindicatio del que puede probar su derecho de propietario frente a cualquiera.

Trasladado este principio a nuestro supuesto de hecho, no sería doloso el vendedor Ticio, si tras la primera venta realizada a non domino, una vez que heredó a Sempronio, reivindica frente al comprador la cosa vendida. Esta afirmación se puede coordinar perfectamente con el pasaje de Ulpiano (D. 44, 4, 4, 32), que contiene el idéntico supuesto de hecho, como hemos visto antes: solo sería doloso el vendedor Ticio si reivindica frente al primer comprador cuando vendió por segunda vez, porque vendió de nuevo una cosa que no tenía in bonis. Ambos pasajes contienen el mismo supuesto de hecho; en ambos el punto de partida es una venta inicial, realizada a non domino por el vendedor Ticio, que luego se hace propietario por heredar a Sempronio. Si antes de la segunda venta reivindica Ticio frente al comprador, no actúa dolosamente, porque como dominus tenía derecho a interponer la acción reivindicatoria desde el más antiguo ius civile frente a cualquiera. Por eso, en este caso, puede utilizar el comprador la exceptio rei venditae et traditae, cuya función es evitar una resolución no equitativa en este caso concreto. Así, puesto que el vendedor puede probar que se hizo propietario después de la venta, su reivindicatio no es dolosa, pero no sería equitativo que venciese en litigio frente al comprador, que pagó por el fundo un precio. Este comprador a non domino puede paralizar, por tanto, su acción reivindicatoria con la exceptio rei venditae et traditae.

En cambio, si el vendedor Ticio lo que pretende es hacer valer su título de dueño (por haber heredado de Sempronio) frente al primero que le compró el fundo, habiendo además hecho una segunda venta, su actuación es claramente dolosa,

${ }^{11}$ En el primer pasaje del título 21, 3 del Digesto, titulado De exceptione rei venditae et traditae, nos describe Ulpiano el caso en el que se aplicaba dicha exceptio. Según D. 21, 3, 1pr, Ulpianus libro LXXVI ad Edictum.- "Marcellus scribit, si alienum fundum vendideris et tuum postea factum petas, hac exceptione (rei venditae et traditae) recte repellendum". Se apoya en la opinión de Marcelo, conforme a la cual, el que vendió un fundo ajeno, si luego se convierte en propietario e interpone una acción, puede ser repelido con razón con esta excepción. Y del mismo Ulpiano, también procedente de los comentarios ad Edictum, es el siguiente pasaje, D. $21,3,1,1$, donde se reafirma que, lo mismo se ha de decir, si el dueño del fundo resultase ser heredero del vendedor, esto es, que la mencionada exceptio también se opondría válidamente contra el heredero del vendedor. 
en cuyo caso la excepción del comprador sería la exceptio in factum comparata vel doli mali, como hemos visto al analizar el pasaje de Ulpiano (D. 44, 4, 4, 32).

Pomponio (D. 21, 3, 2) no nombra expresamente la excepción que sería aplicable, porque el mantenimiento, exactamente, del mismo supuesto de hecho sirve para explicar el funcionamiento, y, en definitiva, la razón de ser de las dos excepciones. Frente al vendedor Ticio el comprador a non domino puede oponer la exceptio rei venditae et traditae si Ticio no fue doloso, o bien la exceptio in factum comparata vel doli mali, si Ticio fue doloso, esto es, si vendió por segunda vez, aunque ya se hubiese hecho dueño. El pasaje de Pomponio, al mantener el mismo supuesto de hecho, precisamente, nos sirve para detectar la diferencia, muy sutil, pero a la vez muy clara, entre una y otra excepción, ya que ambas, por lo demás, tienen un funcionamiento procesal idéntico.

En efecto, en el ámbito del proceso sería indiferente el uso de cualquiera de las dos excepciones. Ambas producían exactamente el mismo resultado, que era la paralización por el comprador a non domino de la acción reivindicatoria del vendedor. Por eso Pomponio no especifica cuál de las dos sería aplicable. Explicando la cuestión por medio de un único caso práctico, que se refiere a la venta por un no dueño de un fundo, se refuerza la idea de que la acción reivindicatoria de Ticio, el vendedor no dueño, no prosperará en ningún caso frente a su comprador, porque este tiene siempre una exceptio (alguna de las dos, o su correspondiente replicatio ${ }^{12}$ ) para vencer en el juicio.

Por otra parte, el pasaje de Pomponio además nos sirve para resaltar el estilo conciso y práctico de los juristas clásicos romanos, que, lejos de dar una compleja explicación, con diferenciación explícita de los dos diversos casos (doloso y no doloso), con sus dos correspondientes excepciones de nombre diferente, proporcionan, sin embargo, de forma sucinta y escueta, la información necesaria

${ }^{12}$ Debemos explicar por qué el triple supuesto de hecho aquí analizado se refiere concretamente al caso en el cual el objeto de la venta a non domino es un fundo, esto es, un bien inmueble. Se trata del caso más amplio, en el que podrían ser aplicables alguna de las dos excepciones o sus correspondientes réplicas. El que vendía una cosa (inmueble o mueble) sin ser dueño hacía una traditio y recibía el precio, entendiéndose la traditio como mero acuerdo de entrega de la cosa que no iba necesariamente acompañado del traslado de la possessio. Esto último sucede, por ejemplo, cuando el que, no siendo dueño, vende un cuadro que permanece expuesto en una exposición, o vende un fundo pignorado o un fundo gravado con un usufructo. Si luego el vendedor no dueño se convierte en dueño por cualquier otro título (por ejemplo, por herencia) y reclama como dueño frente al comprador, entonces este tiene contra aquel la exceptio rei venditae et traditae porque, en efecto, le había vendido la cosa, o la exceptio in factum comparata vel doli mali, si además la había vendido a un tercero. Si, en cambio, era el comprador el que quería reclamar frente al vendedor, que tras la venta le discute el título de propietario, tiene la actio Publiciana contra este, pero solo cuando se trataba de un inmueble y el vendedor retenía la possessio. En cambio, si se trataba de una cosa mueble y la possessio no le fue entregada al comprador, este tiene la actio Publiciana contra el tercero que la posea, pero no contra el vendedor, frente al que tiene la actio empti para que se la entregue. Por tanto, cuando se trata de una cosa mueble frente al vendedor no entrarían en juego ni acción Publiciana ni la correspondiente réplica; si el vendedor la posee, tiene que entregarla, y con mayor motivo si se convirtió en dueño después de la venta. 
para la solución práctica de un supuesto de hecho enunciado de la forma más general posible.

\section{LA ACCIÓN REIVINDICATORIA DEL VENDEDOR A NON DOMINO}

Exactamente el mismo supuesto de hecho con la misma solución, aparece descrito en el tercero de los pasajes mencionados al inicio, que es D. 6, 1, 72 ${ }^{13}$, de Ulpiano libro XVI ad Edictum. El supuesto de hecho es idéntico y también los instrumentos de defensa que puede utilizar el comprador a non domino del fundo: frente a la posible reivindicatio del vendedor tiene una exceptio, y también tiene contra el vendedor la replicatio, si este se opone con la excepción de dominio. Pero la diferencia que presenta este pasaje de Ulpiano, frente al analizado en primer lugar, del mismo jurista y con el mismo supuesto de hecho (D. 44, 4, 4, 32), es que no dice el nombre de la exceptio ni de la replicatio que puede utilizar el comprador. Podemos entender que esta omisión es delibrada, porque Ulpiano quiere dar aquí (igual que Pomponio en D. 21, 3, 2) una solución más general a nuestro supuesto de hecho.

La cuestión a destacar respecto a este tercer pasaje aquí analizado (de Ulpiano D. 6, 1, 72) es que fue insertado por los compiladores en el título 6, 1 del Digesto, titulado De rei vindicatione. Esta inserción tiene su explicación. Se repite el mismo supuesto de hecho que aparece también en otros pasajes porque se pretende reafirmar que un vendedor que no sea dueño no vencería nunca con la reivindicatio frente al comprador, porque este siempre tenía una excepción contra aquel (una de las que hemos mencionado antes). Y, además, el comprador a non domino de un fundo vencería con la actio Publiciana siempre frente al vendedor, si este no era dueño cuando vendió, incluso aunque este oponga la exceptio dominii, porque el comprador tendría una replicatio (una de las que hemos mencionado antes).

Con la inserción del mismo supuesto de hecho en el título del Digesto dedicado a la reivindicatio se pone de relieve que había un caso excepcional, en el que, quien podía probar en juicio que era dominus (el vendedor Ticio, una vez que heredó de Sempronio), nunca vencería con la acción reivindicatoria y, además, sería vencido con una acción Publiciana ${ }^{14}$. Este caso único sería el del vendedor no dueño frente a su comprador.

La aparición del supuesto de hecho por triplicado en el Digesto sirve para poner de relieve la excepcionalidad del caso, descrito de la forma más sucinta y concisa posible, en forma de caso práctico. Pero, además, se pone de relieve la necesaria

${ }^{13}$ D. 6, 1, 72: "Si a Titio fundum emeris Sempronii, et tibi traditus sit pretio soluto, deinde Titius Sempronio heres extiterit, et eundem alii vendiderit et tradiderit, aequius est, ut tu potior sis. Nam et si ipse venditor eam rem a te peteret, exceptione eum summoveres. Sed et si ipse possideret, et tu peteres, adversus exceptionem dominii replicatione utereris".

${ }^{14}$ Lenel, Otto, cit. (n. 6), col. 511, no 564, encuadra este pasaje de Ulpiano libro XVI ad Ed. bajo la rúbrica "De Publiciana in rem actione". En realidad, la ubicación bajo la rúbrica de la reivindicatio, como hicieron los compiladores, destaca más la excepcionalidad del caso en el que, quien puede probar su derecho dominical conforme al ius civile (Ticio), no vencería en juicio frente al propietario pretorio. 
intervención del ius honorarium frente al ius civile, porque con la autorización de las excepciones (y de las réplicas) por el pretor se perseguía la consecución de una solución más equitativa frente al rígido ius civile ${ }^{15}$.

La función que cumplían las excepciones en el procedimiento era la introducción del principio de equidad en la aplicación del ius civile, tal y como nos informa Gayo (4,116): las excepciones tendrían aplicación cuando, frecuentemente, alguien estaría obligado conforme al ius civile, pero no resultaba equitativo condenarle por medio de un iudicium ("saepe enim accidit ut quis iure civilis teneatur, sed iniquum sit eum iudicio condemnari") ${ }^{16}$.

La función del derecho pretorio o ius honorarium era, pues, la de favorecer la equidad del caso concreto frente a la rigidez del ius civile, misión que también aquí cumplen las dos excepciones analizadas (y sus correspondientes réplicas). Desde el más antiguo ius civile, el dominus, esto es, el que puede demostrar su derecho de propietario en juicio, vence siempre frente a cualquiera con la acción reivindicatoria. Pero en ciertos casos, como el que aparece descrito en este supuesto de hecho triplicado, debe intervenir el ius honorarium para corregir el ius civile, ya que no sería equitativo admitir que prospere dicha acción, interpuesta por un vendedor que no era dueño en el momento de la venta (aunque luego se convirtiese en dueño) contra su comprador ${ }^{17}$.

Según el ius civile, tenía el dominium el que podía demostrar su derecho de propiedad en una acción reivindicatoria. Por eso, si Ticio tras la venta inicial $a$ non domino se convierte en dueño, vencería con la acción reivindicatoria frente a cualquiera, incluido el comprador, según el ius civile. Pero la equidad del caso concreto requiere que intervenga el pretor autorizando el uso de una excepción por el comprador, alguna de las dos mencionadas (y sus correspondientes réplicas). La oposición de cualquiera de las dos excepciones conduciría al mismo resultado: la paralización de la acción reivindicatoria del que puede demostrar su derecho

${ }^{15}$ Ya Lenel, Otto, Über Ursprung und Entwicklung der Exceptionen (Heidelberg, Gustav Koester, 1876), p. 98, demostró, en contra de la doctrina dominante en su época, que las excepciones pertenecían al derecho pretorio: "wir dürfen uns aus voller Überzeugung der Reihe derjenigen Schriftsteller anschliessen, welche der Meinung sind, dass alle Exceptionen dem prätorischen Rechte angehören".

${ }^{16}$ Sobre la naturaleza de las excepciones en el ámbito de los iudicia bonae fidei, véase METRO, Antonino, Exceptio doli e iudicia bonae fidei, en D'Ippolito, Federico M. (coord.) Filia. Scritti per Gennaro Franciosi (Napoli, Satura Editrice, 2007), III, p. 1753: la inherencia automática de la exceptio doli en los iudicia bonae fidei no puede ser reconducida a los juristas clásicos. Pero esto, según Metro, no quiere decir que para los juristas clásicos fuese extraña la idea de que la valoración del dolo entraba automáticamente en el ámbito de la buena fe; lo que debe considerarse inherente a los juicios de buena fe es la valoración del dolo, no la de la exceptio.

${ }^{17}$ Las dos excepciones aquí analizadas cumplen, pues, la misión que describió ARIAS RAMOS, José, Precedentes supletorios de la exceptio en el procedimiento de las Legis Actiones, en AHDE., 16 (1945), p. 723, en la exceptio se alega una circunstancia que hace que aparezca como injusto acceder, en aquel caso concreto, a la pretensión del actor. Son modalidades de defensio del demandado en las que este deja intacta la intentio, es decir, la legalidad y exactitud del derecho alegado por el actor, pero alega una circunstancia que frena o impide la puesta en vigor de tal derecho. 
de propietario, porque, en este caso concreto, no sería equitativo, ya que había realizado una venta a non domino.

Se trata de explicar, con el mismo supuesto de hecho, que, aunque el ius civile ampara con la reivindicatio a todo el que puede demostrar en juicio su derecho de propietario, sin embargo, en el caso específico de una venta a non domino, aunque el vendedor adquiera luego la condición de propietario, resulta más equitativo que el pretor ampare al primer comprador. Este comprador a non domino es mantenido en su adquisición frente a su propio vendedor gracias a la autorización de alguna de las dos excepciones por el pretor.

Insertando este supuesto de hecho en otro título del Digesto (Tit. 6, 1), el dedicado a la acción reivindicatoria del dominus, se deja claro que el vendedor no dueño no vencería nunca con la reivindicatio frente al comprador de la cosa, aunque luego se convierta en dueño. Pero, además, se deja clara la distinción de este frente a otro caso, que presenta matices diferentes: el del vendedor que era dueño en el momento de la venta, que luego reivindica frente al comprador. Los juristas para este caso nos dan una solución distinta.

Ulpiano en D. 21, 2, $17^{18}$ afirma que no cabe ninguna duda de que el comprador tenía la exceptio doli frente al vendedor, si este reivindica la cosa que él mismo vendió, aunque buscase el reconocimiento del dominium en virtud de otro derecho (alio iure). Según Ulpiano, impropiamente intenta el vendedor conseguir en juicio (evincere) la cosa vendida por él. El comprador entonces podría elegir entre retener la cosa, paralizando la acción por medio de la exceptio doli, o, si prefiere, una vez despojado de la cosa, conseguir el doble, exigiendo responsabilidad por evicción al vendedor. Respecto a nuestro supuesto de hecho triplicado, la diferencia es que la exceptio doli aquí se concede de forma genérica, porque el vendedor actúa en contra de la buena fe contractual. En cambio, en la venta a non domino, la exceptio se fundamente específicamente en la venta, que, efectivamente, fue realizada por quien no era dueño.

En consecuencia, se puede afirmar que en la compraventa, la reivindicación del propio vendedor convertido en dominus frente al comprador era dolosa, aunque, si era dueño en el momento de la venta podía constituir un caso peculiar de responsabilidad por evicción. Por eso se incluyó este pasaje en el título 21, 2 del Digesto, de evictione. Aquí tiene el comprador la posibilidad de optar entre oponer la exceptio doli frente a la acción del vendedor, o exigirle a este la responsabilidad por evicción. El caso más grave, es, pues, el que aparece en nuestro triple supuesto de hecho, que se refiere al caso en que se realizó una venta a non domino.

\section{LA FÓRMULA DE LAS EXCEPCIONES}

Hemos constatado que, en los tres pasajes del Digesto aquí analizados, que contienen el mismo supuesto de hecho, este se utiliza para justificar la aplicación

${ }^{18}$ D. 21, 2, 17, Ulpianus libro XXIX ad Sabinum.- "Vindicantem venditorem rem, quam ipse vendidit, exceptione doli posse summoveri nemini dubium est, quamvis alio iure dominium quaesierit; improbe enim rem a se distractam evincere conatur. Eligere autem emptor potest, utrum rem velit retinere intentione per exceptionem elisa, an potius re ablata ex causa stipulationis duplum consequi". 
de dos instrumentos procesales - una excepción y una réplica- en el caso de que se interpusieran contrapuestas acciones reivindicatorias entre un vendedor no dueño (acción reivindicatoria) y su comprador (acción Publiciana).

Las excepciones aquí analizadas se insertarían en la fórmula de la acción reivindicatoria, cuando el reivindicante era un vendedor no dueño. Si Ticio interponía una reivindicatio reclamando la propiedad de una cosa, el pretor ordenaba al juez que (según su arbitrio) condenara al demandado a restituirla o bien al pago de la cuantía que se estimase, si resulta que Ticio no se la había vendido y entregado al demandado (si non vendidit et tradidit-exceptio rei venditae et tradita ${ }^{19}$-) o si no le había vendido la cosa de hecho o no había actuado con dolo malo (si non in factum comparata sit, si in ea re nibil dolo malo factum sit, -exceptio in factum comparata vel doli mali ${ }^{20}-$ ). De esta forma, la reivindicatio del vendedor frente al comprador (a non domino) quedaría siempre y en todo caso paralizada con la aplicación de una de las dos excepciones.

Y en el caso de la replicatio, esta se insertaría en la fórmula de la actio Publiciana que el comprador interponía contra Ticio, el vendedor no dueño del fundo. Si este oponía la exceptio dominii (si non suus esset), el pretor ordenaba al juez que (según su arbitrio) condenase al demandado Ticio a restituir la cosa o al pago de la cuantía que se estimase, si resulta que este se la había vendido (replicatio rei venditae et traditae) o si, además, se la había vendido a un tercero (replicatio in factum comparata vel doli mali). Por tanto, el que vendió no siendo dueño perdería siempre el litigio, en el caso de que el comprador interpusiese contra él la actio Publiciana.

\section{MANTENimiento DEl SUPUESTO DE HECHO POR LOS COMPILAdORES}

El supuesto de hecho que aparece por triplicado en estos pasajes del Digesto había sido ya planteado y resuelto por Juliano. Pero se repite el mismo supuesto de hecho por los juristas posteriores (Pomponio y Ulpiano, que reconocen la autoría de Juliano), porque era la mejor forma de explicar, conjuntamente en un único supuesto práctico y de forma sumaria, el funcionamiento de los complicados instrumentos procesales (dos excepciones y dos réplicas) que servían para que el pretor impusiese la equidad frente a la rigidez del ius civile cuando se había producido una venta de un fundo por quien no era dueño.

Tomando en consideración los pasajes aquí analizados, que contienen la exposición de un mismo sucinto supuesto de hecho, se pueden extraer otras dos conclusiones. Por un lado, que existía una total certeza y cristalización de

\footnotetext{
${ }^{19}$ Esta es la formulación de la exceptio rei venditae et traditae según LeneL, Otto, Das Edictum Perpetuum. Ein Versuch zu seiner Wiederherstellung ${ }^{3}$ (1883, Lepizig, Tauchnitz, 1927), p. 511: si non As As fundum q.d.r.a. No No vendidit et tradidit. También la de WACKE, Andreas, $L a$ "exceptio doli" en el derecho romano clásico y la "Verwirkung" en el derecho alemán moderno, en Paricio SerRano, Javier (coord.), Derecho romano de obligaciones: homenaje al profesor José Luis Murga Gener (Madrid, Centro de Estudios Ramón Areces, 1994), p. 978.

${ }^{20}$ Según Lenel, Otto, Das Edictum Perpetuum. Ein Versuch zu seiner Wiederherstellung, cit. (n. 20), p. 512: si in ea re nibil dolo malo Ai Ai factum sit neque fiat.
} 
las instituciones jurídicas romanas, como vemos en este concreto ejemplo de la emptio venditio, tanto en su aspecto sustantivo como procesal, desde la época del jurista Juliano. Y, por otro lado, que fueron las obras de los juristas posteriores, especialmente de Ulpiano (D. 44, 4, 4, 32 y D. 6, 1, 72, del mismo título ad Edictum), las que allanaron y simplificaron el trabajo de confección del Digesto a los compiladores de Justiniano.

En efecto, un par de siglos después, los compiladores conservaron ese mismo esquema práctico de los juristas clásicos para, ubicándolo en títulos diferentes del Digesto, fundamentar la explicación, de la forma más concisa posible, de las dos excepciones (con sus correspondientes réplicas) que podía utilizar el comprador cuando el vendedor no era dueño en el momento de la venta.

El mantenimiento del mismo supuesto de hecho en diferentes títulos del Digesto obedeció probablemente a la especial dificultad que presentaba la cuestión, cuya resolución se planteaba, ya que el reconocimiento de sus matices diferenciadores requería una gran sutileza y un fino sentido jurídico que los compiladores indudablemente tenían, y que era, además, imprescindible para la comprensión de los textos de los juristas clásicos. Por eso es posible sostener como hipótesis que, conscientes de que repetían el mismo supuesto de hecho por triplicado, los compiladores lo habrían mantenido, siendo admisible incluso que hubiesen hecho algún cambio en las palabras con las que se describía la solución propuesta. Porque ante el un mismo supuesto de hecho, la solución propuesta era la misma: que era más equitativo que el primer comprador fuese protegido. Pero las palabras utilizadas eran distintas, en D. 44, 4, 4, 32 son aequius esse praetorem te tueri, mientras que en D. 21, 3, 2 se dice aequius esse priorem te tueri, y en D. 6, 1, 72 aequius est, ut tu potior sis.

En este sentido sí se podría admitir la existencia de una cierta intervención de los compiladores que, conscientes de la repetición del supuesto de hecho, podrían haber pretendido disimularla con esta sutil alteración de las palabras. Pero esta actuación, en definitiva, no introducía ningún cambio en el sentido ni en el significado de la solución propuesta y además, también puede admitirse que esas hubiesen sido las mismas palabras que utilizaron los propios juristas clásicos. La discusión acerca de la supuesta alteración de la literalidad de los textos por los compiladores aquí, por tanto, carece de relevancia.

Creemos haber encontrado, entonces, una explicación a la aparición por triplicado en el Digesto del mismo supuesto de hecho. Los compiladores de Justiniano lo habrían mantenido porque debieron darse cuenta, igual que los juristas clásicos, de que era la forma más idónea de explicar muy sucintamente, con fundamento en un caso práctico, la existencia y el funcionamiento de las dos específicas excepciones, con sus concordantes réplicas, cuyo uso se admitió cuando la compraventa se había realizado a non domino ${ }^{21}$. Por tanto, estas tres llamadas luego leyes gemelas (leges geminatae) cumplirían la misión que Verrey ${ }^{22}$ les

\footnotetext{
${ }^{21}$ No era una exceptio doli generalis, sino propia y específica de la emptio venditio. Véase Caravaglos, Adelaide, Exceptio doli generalis e actio de dolo malo: prospettive diacroniche, en Index, 39 (2011), pp. 151-154.

${ }^{22}$ Verrey, Olivier, Leges geminatae à deux auters et compilation du Digeste (Lausana, Lausana
} 
reconoció a estas de forma general: han sido toleradas y aceptadas por la comisión (de Justiniano) porque no solamente no contrarían las finalidades señaladas por Justiniano, sino, al contrario, hacen la lectura y la comprensión de las pandectas aún más enriquecedora.

\section{VII. ÚNICA FINALIDAD Y DOS EXCEPCIONES}

A modo de conclusión se puede afirmar, pues, que la existencia de la exceptio rei comparata vel doli mali y de la exceptio rei venditae et traditae (y sus correspondientes réplicas) obedecía a una única finalidad, consistente en impedir que el que vendió una cosa no siendo dueño pudiese vencer frente a su comprador en un litigio posterior, iniciado entre ellos con una acción real. La utilización de estas dos excepciones vino impuesta por la propia naturaleza del negocio jurídico celebrado, la emptio venditio, que producía plenos efectos desde su perfección por medio del consensus de las partes sobre la cosa objeto de venta y el precio. La venta a non domino era plenamente eficaz entre comprador y vendedor, y esta circunstancia luego nunca cambiaba aunque el vendedor se convirtiese en dominus después de la venta, y menos aún si había este celebrado luego una segunda venta. La existencia de estas dos excepciones (y sus correspondientes réplicas) demuestra que de una venta a non domino nunca podrá beneficiarse el que vendió no siendo dueño, ya que, aunque luego este se convierta en propietario, no podrá nunca vencer en un juicio reivindicatorio frente a quien fue su comprador.

\section{BiBLIOGRAFÍA}

Arangio-Ruiz, Vincenzo, La compravendita in diritto romano (1956, reimpresión, Napoli, Jovene, 1987), I.

ARIas Ramos, José, Precedentes supletorios de la exceptio en el procedimiento de las Legis Actiones, en $A H D E ., 16$ (1945), pp. 720-732.

CAnnata, Carlo Augusto, La compravendita consensuale romana: significato di una struttura, en VACCA, Letizia (a cura di), Vendita e trasferimento della proprietà nella prospettiva storico-comparatistica (Milano, Giuffré, 1991), II, pp. 413-432.

Caravaglios, Adelaide, Exceptio doli generalis e actio de dolo malo: prospettive diacroniche, en Index, 39 (2011), pp. 151-154.

García Garrido, Manuel Jesús, Redacciones coincidentes ("leges geminatae”) y casos jurisprudenciales semejantes ("capita similia") en Estudios de derecho romano en honor de Álvaro d'Ors (Pamplona, EunsA, 1987), I, pp. 517-538.

Hernando Lera, Julio, Una corrección paligenésica al libro 16 de Ulpiano ad Edictum, en Boletín de la Facultad de Derecho, 10-11 (1996, UNED), pp. 143-160.

KoschaKer, Paul, Fr.4.32 D.44.4 Contributo alla storia della convalida nel diritto romano, en IURA, 4 (1953), pp. 1-89.

Lenel, Otto, Das Edictum Perpetuum. Ein Versuch zu seiner Wiederherstellung ${ }^{3}$ (1883, Lepizig, Tauchnitz, 1927).

Presses Centrales, 1973), p. 190, reconoce la existencia de leges geminatae aunque procedan de diferentes juristas. 
—Palingenesia Iuris Civilis (Graz (Austria), Akademische Druck-U. Verlagsanstalt, 1960).

- Über Ursprung und Entwicklung der Exceptionen (Heidelberg, Gustav Koester, 1876).

López Pedreira, Adela, El problema de la doble venta de una cosa: del derecho romano clásico al artículo 1473 del Código Civil español en Murillo Villar, Alfonso (coord.), La responsabilidad civil: de Roma al derecho moderno, IV Congreso Internacional y VII Congreso Iberoamericano de Derecho Romano (Burgos, Universidad de Burgos, 2001), pp. 455-468.

Metro, Antonino, Exceptio doli e iudicia bonae fidei, en D'Ippolito, Federico M. (coord.) Filia. Scritti per Gennaro Franciosi (Napoli, Satura Editrice, 2007), III, pp. 1731-1754.

Verrey, Olivier, Leges geminatae à deux auters et compilation du Digeste (Lausana Presses Centrales, Lausanne, 1973).

WACKE, Andreas, La "exceptio doli" en el derecho romano clásico y la "Verwirkung" en el derecho alemán moderno, en PARICIO SerRANO, Javier (coord.), Derecho romano de obligaciones: homenaje al profesor José Luis Murga Gener (Madrid, Centro de Estudios Ramón Areces, 1994), pp. 977-997. 